\title{
Orgasm and SCl: what do we know?
}

\author{
Marcalee Alexander ${ }^{1,2,3} \cdot$ Lesley Marson ${ }^{4,5}$
}

Received: 5 July 2017 / Revised: 9 September 2017 / Accepted: 13 September 2017 / Published online: 20 December 2017

(c) International Spinal Cord Society 2018

\begin{abstract}
Study design narrative review

Objectives To determine the percentage of persons with SCI able to achieve orgasm and ejaculation, the associations between ejaculation and orgasm and the subjective and autonomic findings during these events, and the potential benefits with regards to spasticity.

Setting Two American medical centers

Methods Data bases were searched for the terms orgasm and SCI and ejaculation and SCI. Search criteria were human studies published in English from 1990 to 12/2/2016.

Results Approximately $50 \%$ of sexually active men and women report orgasmic ability after SCI. There is a relative inability of persons with complete lower motor neuron injuries affecting the sacral segments to achieve orgasm. Time to orgasm is longer in persons with SCIs than able-bodied (AB) persons. With orgasm, elevated blood pressure (BP) occurs after SCI in a similar fashion to $\mathrm{AB}$ persons. With penile vibratory stimulation and electroejaculation, BP elevation is common and prophylaxis is recommended in persons with injuries at T6 and above. Dry orgasm occurs approximately $13 \%$ of times in males. Midodrine, vibratory stimulation, clitoral vacuum suction, and 4-aminopyridine may improve orgasmic potential.

Conclusions Depending on level and severity of injury, persons with SCIs can achieve orgasm. Sympathetically mediated changes occur during sexual response with culmination at orgasm. Future research should address benefits of orgasm. Additionally, inherent biases associated with studying orgasm must be considered.
\end{abstract}

Electronic supplementary material The online version of this article (https://doi.org/10.1038/s41393-017-0020-8) contains supplementary material, which is available to authorized users.

\section{Marcalee Alexander}

spinalcordmd@live.com

1 Department of Physical Medicine and Rehabilitation, University of Alabama at Birmingham School of Medicine, Birmingham, AL, USA

2 Department of Physical Medicine and Rehabilitation, Harvard School of Medicine, Boston, MA, USA

3 Birmingham VA Medical Center, Birmingham, AL, USA

4 Dignify Therapeutics, Research Triangle Park, NC, USA

5 Department of Urology, School of Medicine, and Division of Pharmacoengineering and Molecular Pharmaceutics, Eshelman School of Pharmacy, University of North Carolina, Chapel Hill, NC, USA

\section{Introduction}

Sexuality is an important concern for persons with and without spinal cord injuries (SCIs) [1]. Desire for affection and intimacy, gender expression and preferences, participation in sexual activities, arousal, and orgasm are all components of sexuality. Unfortunately, sexual satisfaction, frequency of activities, and overall interest decrease after SCI [2-7].

The sexual response cycle generally culminates with orgasm. However, as per a recent publication, "The definition of orgasm is not an easy task. The way of experiencing it is subjective" [8]. In able-bodied women orgasm has been defined as "a variable, transient peak sensation of intense pleasure, creating an altered state of consciousness, usually accompanied by involuntary, rhythmic contractions of the pelvic striated circumvaginal musculature, with concomitant uterine and anal contractions and myotonia that resolves the sexually induced vasocongestion (sometimes only partially), usually with an induction of well-being and contentment" [9]. In men, orgasm has been described as "the result of cerebral processing of pudendal nerve sensory 
stimuli resulting from increased pressure in the posterior urethra, sensory stimuli arising from the veramontanum and contraction of the urethral bulb and accessory sexual organs [10].

Orgasm is well-known to occur in persons with SCIs [2-7, 11, 12]; however, similar to able-bodied (AB) persons, most studies rely on self-report data and infrequently, concomitant measure of autonomic responses [13]. Unfortunately, the potential for orgasm is often disregarded after SCI and orgasm is often equated with ejaculation. Significant research assesses ejaculation after SCI and its benefits, primarily decreased spasticity, but sparse data examines orgasm. Opinions also differ regarding the association and frequency of autonomic dysreflexia (AD) with orgasm $[13,14]$. In order to optimize the ability to achieve orgasm in persons with SCIs, it is important to understand its characteristics. The goals of this review are therefore to (1) determine the methods and ability of persons with varying patterns of SCIs to achieve orgasm along with associated subjective and autonomic responses and (2) determine the associations between orgasm and ejaculation and effects on spasticity. For information regarding the neurophysiologic aspects, the reader is referred to a recent review on the neurologic control of orgasm with regards to spinal cord lesions [15].

\section{Methods}

A search of Pub Med, CINAHL Complete and the Cochrane databases was conducted with results detailed in Fig. 1. Search criteria included English language, 1990 to $12 / 2 / 2016$, only human studies. Specific questions included

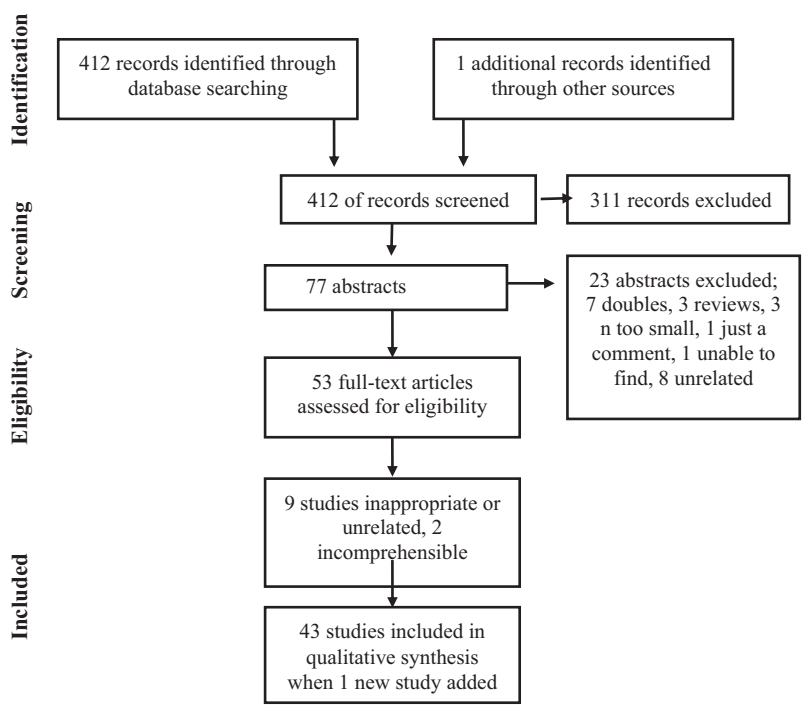

Fig. 1 Search results
What percent of persons with SCIs can achieve orgasms and are there subgroups with more capacity to achieve orgasm? What techniques used to achieve orgasm? What are the autonomic and subjective characteristics of orgasm and ejaculation and do they always coexist? What is known about ejaculation and/or orgasm and spasticity? Search terms included (1) orgasm and SCI, (2) ejaculation and SCI. The complete list of abstracts was then reviewed for relevance to the research questions and case reports, reviews, met analyses and irrelevant and duplicative abstracts were removed. Original articles were then obtained from this revised list of abstracts and 53 articles were reviewed independently by both authors. After review of the complete articles, 11 were deleted due to irrelevance to the questions or not meeting review criteria. A total of 42 articles were placed in appropriate tables to determine their relevance to specific research questions, and both authors concurred regarding individual points. After the initial review, just prior to study submission, one additional paper was added that was identified as relevant [16]. When articles were particularly germaine to the topic and included independent information but the same subjects, all references were listed in the same row on the table. Additionally, if a single article pertained to multiple tables, appropriate information was included on all tables. Due to the volume of relevant information, all tables are included as supplementary material that are available on line.

\section{Results}

\section{Studies reporting ability to achieve orgasm}

Twenty-three studies addressing the percentage of persons with SCI with the ability to achieve orgasm and techniques used to achieve orgasm are presented in Supplementary Table 1 [2-7, 11, 12, 16-30]. Among these, 15 were cross sectional questionnaire or interview studies [2-7, 16, 19, 20, 22-24, 26, 28, 30]. Two studies discussed in three separate papers were laboratory based controlled analyses of the ability to achieve orgasm [18, 21, 27]. Two double-blind placebo controlled clinical trials assessed the impact of the treatment on orgasmic function as a secondary outcome via questionnaire [17, 29]. Two studies assessed potentially orgasmic sensations during ejaculation using penile vibratory stimulation (PVS) $[12,25]$ while one prospective study evaluated the ability to achieve orgasm with PVS and midodrine [11].

One shortfall identified in these reports is that generally to achieve orgasm participation in sexual activity is required and sexual activity can cease post SCI. This issue is often not discussed; nor is there a consistent definition or discussion of what comprises sexual activity. Many of the 
reports provide inadequate data to determine the association of orgasm with specific injury patterns, many studies focus on intercourse, and in males studies often limit their discussion to the occurrence of ejaculation. Although the number of men with SCI is approximately 4 times that of women, there is less information available about male orgasm. In the male population, there were a total 604 men studied of which 539 were sexually active. Of these 241 reported they achieved orgasm; hence, $40 \%$ of all males and $45 \%$ of sexually active males achieved orgasm. In the female population, there were 1544 women studied of which 1168 were sexually active and 654 reported orgasms. Thus $42 \%$ of all females and $56 \%$ of sexually active females reported orgasm. If we combine all data, a total of 942/2241 (42\%) of all persons with SCIs reported having orgasms or 942/1811 (52\%) sexually active persons with SCIs.

Reports assessing the impact of treatments on the ability to achieve orgasm showed $59 \%$ of men of 158 men who had failed to ejaculate at home or during baseline PVS could have orgasm with the addition of midodrine [11]. This study was not blinded and midodrine dose was increased up to 30 $\mathrm{mg}$ in order to optimize the likelihood of orgasm, thus the issue of bias must be considered. A prospective, unblinded study of 170 men receiving sildenafil noted that men with preexisting orgasms were 5 times as likely as those without to respond to the drug [17]. Moreover, their abilities to achieve orgasm, as measured by the International Index of Erectile Function (IIEF), improved with use of sildenafil [17]. In two double-blind placebo-controlled studies (DBPC) with 357 male and 58 female subjects, administration of the drug 4-aminopyridine, for spasticity, showed a significant increase in the orgasm domain of the IIEF in one study out of two; however, there were no significant changes in females [29].

Regarding techniques to achieve orgasm, only one questionnaire study in females detailed where women stimulated themselves to achieve orgasm, noting the stimulus was generally genital or genital plus breast [3]. In contrast, in a laboratory based study [18] all women chose genital stimulation. In males with SCIs, although it is often indicated that stimulation around the level of injury can be arousing, published studies have identified only the use of genital stimulation to achieve orgasm [21]. Another questionnaire study indicated approximately $80 \%$ of 199 men studied [23] reported trying to achieve ejaculation post SCI and of these $26 \%$ reported using hand stimulation, $21 \%$ engaged in intercourse and $14 \%$ used vibratory stimulation.

The occurrence of orgasm with specific types of injuries is infrequently addressed. One questionnaire study of males indicated $51 \%$ of 16 with complete tetraplegia, $66 \%$ of 6 with incomplete tetraplegia, $25 \%$ of 12 with complete paraplegia and $75 \%$ of 4 with incomplete paraplegia had orgasms [4]. In another report [24] 59\% of 44 males with
AIS A, $79 \%$ of 14 with AIS B, $55 \%$ of 11 with AIS C, and $74 \%$ of 23 with AIS D SCIs had orgasms. However, neither report limited their assessments to sexually active persons, which is generally a prerequisite to orgasm, and this issue was handled differently in the reports. In the first paper [4] there is a column attributed to, 'do not know' if they had orgasm. If we surmise these men were not sexually active, the rate of orgasm goes up in men with complete tetraplegia to 66 and $27 \%$ in men with complete paraplegia. In contrast, in the second paper [24] if we only consider the percent of men that said they were sexually active, then $87 \%$ of AIS A, $92 \%$ of AIS B, $100 \%$ of AIS C, and over $100 \%$ (actually $113 \%$ ) of AIS D subjects would have reported orgasms. Similarly, the issue of not participating in sexual activities or not knowing whether the person can achieve specific sexual responses is important in female studies. In a questionnaire study of 25 females, $40 \%$ of 5 with complete tetraplegia reported orgasm while $40 \%$ did not know, $77 \%$ of 9 with incomplete tetraplegia reported orgasm whereas $11 \%$ did not know, $25 \%$ of 4 women with complete paraplegia reported orgasm while 50\% did not know, and $71 \%$ of 7 women with incomplete paraplegia reported orgasm whereas 14\% did not know [5]. Clearly, these analyses identify the issues of over and underreporting associated with retrospective self-report questionnaire studies.

Laboratory studies with detailed neurologic examination of persons with SCIs and able-bodied controls have been performed to address the deficiencies of self-report data. Men [21] and women [18] with SCI (50\% of $45 ; 44 \%$ of 52) were significantly less likely than $\mathrm{AB}$ controls ( $100 \%$ of 16 ; $100 \%$ of 21$)$ to achieve orgasm in a laboratory $(p<.001$; $p=.001)$. With respect to the pattern of SCI, of 45 men, $50 \%$ of 29 men with complete injuries and $84 \%$ of 16 men with incomplete injuries reported orgasmic ability at home ( $p=.018$ ) while $28 \%$ of 29 men with complete injuries and $79 \%$ of 16 men with incomplete injuries reported orgasms in the laboratory $(p<.001)$. Of men with complete lower motor neuron (LMN) injury affecting their sacral segments none $(0 / 4)$ reported orgasm at home compared to $68 \%$ of 41 with all other levels and degrees of injury $(p=.007)$ and $0 / 4$ vs. 55\% of 41 had orgasms in the laboratory $(p=.04)$ [21]. Similarly, of 62 females [18], only $17 \%$ or 1 of 6 women with complete LMN dysfunction affecting their S2-S5 spinal segment reported orgasm at home vs. 59\% of 56 women with all other degrees of SCI $(p=.048)$, with $17 \%$ of 6 vs. $46 \%$ of 56 reporting orgasm in the lab $(p=.16)$. Although the potential for bias remains as orgasm is a subjective phenomenon, these reports have the benefit of laboratory-based data and $\mathrm{AB}$ controls. Collectively, these reports $[18,21]$ document there is a decreased ability to achieve orgasm after SCI and that, within the SCI population, both women and men with complete LMN injuries affecting their sacral segments are significantly less 
likely to achieve orgasm than individuals with all other levels and degrees of SCIs.

In another report [11] the occurrence of orgasm during ejaculation was described. A total of 59\% of 158 men who had failed to ejaculate with PVS alone reported orgasm with the addition of midodrine. Furthermore, the perception of orgasm was associated with anterograde ejaculation. Of 70 with anterograde ejaculation, $99 \%$ reported orgasm compared to $54 \%$ of 32 who did not achieve anterograde ejaculation. Injuries below T10, LMN lesions and a lack of somatic responses with stimulation were significantly related to the absence of orgasm and 13\% had dry orgasm. Courtois [12, 25] performed 2 studies which described sensations associated with orgasm; thus, these studies are included in Supplementary Table 1 as the word orgasm is used in the title; however, the word orgasm was not used in discussion with the subjects. Rather, events associated with ejaculation were reported as the outcome, therefore, this information is discussed under ejaculation.

Taken together these studies indicate that it is possible to achieve orgasm after SCI and that the use of midodrine, sildenafil and 4-aminopyridine may be pro-orgasmic. Persons with complete LMN injuries affecting the sacral segments are less likely than persons with all other levels and degrees of SCI to achieve orgasm.

\section{Studies reporting ejaculation}

Studies related to the ability to achieve ejaculation are in Supplementary Table 2 [25, 31-40]. There is one cross sectional study querying the natural ability to ejaculate [40] and seven assessing the efficacy of PVS to achieve ejaculation in men with SCIs [31, 32, 34-37, 39] including three retrospective chart reviews [35-37]. There was one doubleblind placebo controlled (DBPC) clinical trial that discussed ejaculation with the treatment of erectile dysfunction [38] and one report that discussed the negative impact of the baclofen pump, an antispasticity therapy, on ejaculation [33]. The use of $100 \mathrm{~Hz}$ frequency and $2.5 \mathrm{~mm}$ of amplitude for PVS was shown to have optimal efficacy for producing ejaculation [31]. Those subjects who had cord lesions at and below T10 were more likely to ejaculate if they had an intact hip flexion or bulbocavernosus reflex (BCR); however, without these reflexes ejaculation was unlikely [32, 35]. In a retrospective review of 123 patients who underwent 204 trials of PVS [35], based upon level of injury, subjects with cervical injuries ejaculated $71 \%$ of the time, those with T1-T6 ejaculated $73 \%$ of the time and those with T7-T12 injuries ejaculated $35 \%$ of the time. For those patients who were below the cervical level, if there was no hip flexion or BCR reflex, 0/21 patients achieved ejaculation. Furthermore, patients with a penile prosthesis were less likely to achieve ejaculation [32] and block of the dorsal penile nerve prevented ejaculation [34] as did baclofen pump implantation [33]. In a retrospective review of 297 men who underwent 965 PVS trials [34], the use of 2 vibrators increased the percentage of men ejaculating by $22 \%$ as compared to just one vibrator. The same group also reported [41] an ejaculatory success rate of $77 \%$ in 30 men through the use of the viberect-X3 (Reflexonic, Frederick, MD, USA) which is designed to stimulate both sides of the penis simultaneously. Soler et al. [39] reported results of the addition of midodrine to stimulate ejaculation in men who were unable to achieve ejaculation naturally or with PVS. Of 158 males, $65 \%$ achieved retrograde or anterograde ejaculation. These results were broken down as $62 \%$ of men with tetraplegia, $69 \%$ with paraplegia above T6, $46 \%$ with paraplegia $\mathrm{T} 7-\mathrm{T} 10$ and $79 \%$ with paraplegia at or below T11.

Courtois et al. $[25,37]$ reported results of a progressive protocol to stimulate ejaculation consisting of masturbation (10 min masturbation, $10 \mathrm{~min}$ of video alone, $10 \mathrm{~min}$ of both) followed by PVS (Ferticare vibrator at $120 \mathrm{~Hz}, 3 \mathrm{~mm}$ amplitude used for 3 min stim and 1 min of rest with max of six trials). If this did not produce ejaculation, PVS was coupled with midodrine $(5 \mathrm{mg}$ ingested $30 \mathrm{~min}$ before PVS protocol, increased by $5 \mathrm{mg}$ with each negative test up to 30 $\mathrm{mg}$ ) to achieve ejaculation. Tests were performed a week apart and continued until men achieved either retrograde and or anterograde ejaculation. In 45 of 60 men who completed the protocol and were evaluated retrospectively, $11 \%$ ejaculated with natural stimulation, $56 \%$ ejaculated with the addition of PVS and $22 \%$ achieved ejaculation with addition of midodrine [37]. Prospectively, in 81 men [25] these techniques resulted in $91 \%$ achieving ejaculation; however, neither report documents whether the men reported orgasm. In the prospective study, we do not know the breakdown of complete vs. incomplete injuries by level; however, $49 \%$ of subjects had complete injuries and 51\% incomplete. Ejaculation occurred in $83 \%$ of men with C2-T2 lesions, 93\% with T3-T6 lesions, $100 \%$ with T7-T10 lesions, $67 \%$ with T11-L2 lesions, and $100 \%$ with lesions at L3 and below.

The studies of Soler and Courtois both had a relatively large number of subjects but were not controlled or blinded. In contrast, in a small double-blind placebo-controlled study of 20 men with SCIs [42] above T10 who underwent one PVS trial followed by 3 subsequent trials in association with midodrine up to a maximal dose of $22.5 \mathrm{mg}$, the authors reported that $1 / 10$ subjects from the midodrine group and $2 / 10$ from the placebo group reached ejaculation. These results are in contrast to others. Thus, the overall low success rate in conjunction with the small sample size must be considered along with the impact of the informed consent process and nocebo and placebo effects and potential research bias all of these studies. In summary, these reports 
demonstrate that men with complete SCIs can experience ejaculation and it is possible to improve the ability of men with SCIs to achieve ejaculation. However, the lack of a question specifically asking about orgasm in the Courtois reports [12, 25, 37], the lack of documentation of ejaculation in the Sipski report [21] and the 13\% occurrence of dry orgasm in the Soler report [11] highlight the potential inaccuracies in equating orgasm and ejaculation in men with SCIs.

\section{Characteristics of orgasm and ejaculation}

Supplementary Table 3 documents studies with data regarding the subjective and autonomic characteristics of orgasm and ejaculation. With regards to orgasmic latency, in one study with $n$ of 231 it is reported that about $50 \%$ of women were orgasmic after injury and of these 43 reported time to achieve orgasm after SCI was longer than prior to injury [3]. This was also demonstrated in a laboratory study [18]. Mean time to orgasm was significantly greater in women with SCIs $(n=62)$ than AB women $(n=21)(26$ $\min$ vs. $16 \mathrm{~min})$; however, in men with SCIs $(n=45)$ vs. $\mathrm{AB}$ men $(n=16)(19 \mathrm{~min}$ vs. $16 \mathrm{~min})$ this difference was not statistically significant [21].

Intensity of orgasm was less in $43 \%$ of 231 women in the aforementioned report, [3] whereas, Ferreiro-Velasco et al. [19] reported $72 \%$ of 19 women who were orgasmic after SCI had more difficulty achieving less pleasurable orgasms. Only one study [5] assessed multiple orgasms and reported that 6 of 11 women who were orgasmic after SCI had multiple orgasms. In a laboratory based study [18], descriptions of orgasmic sensations could not be distinguished between $\mathrm{AB}$ women vs. women with complete or incomplete SCIs. In a questionnaire study of 234 orgasmic women with SCIs [28], 8\% reported orgasms were the same as before the injury. Twenty-five percent reported positive sensations including comments like "being in heaven", $13 \%$ were satisfied with orgasms and $31 \%$ reported they were relaxing. Results were conflicting however, in that, despite reporting orgasms, 3\% reported unpleasant sensations in association with orgasm and $8 \%$ reported that they have not experienced orgasm after SCI.

Sensations associated with ejaculation were studied retrospectively in 45 men [37]. Spasms, shivering, goose bumps, hot flushes, pleasure and a feeling of imminent ejaculation were more common during ejaculatory than non-ejaculatory events and more likely with the use of midodrine. Headaches were only reported during positive tests and were more likely with midodrine [37]. Sensations were also assessed in 81 men prospectively with or without ejaculation [25]. In this study, 11 questions related to autonomic hyperreflexia, 9 to general autonomic arousal,
8 to muscular responses and 5 were about cardiovascular and respiratory responses. Not surprisingly, increased sensations were present when ejaculation occurred. Moreover, it was reported that increased sensations were noted with ejaculation when $\mathrm{AD}$, as defined by an increase in blood pressure (BP) over $20 \mathrm{mmHg}$ occurred. Bird et al. [35] reported on "somatic responses" of 44 men during PVS including abdominal contractions below the injury level, thigh abduction and adduction, lower extremity spasms, lower extremity withdrawal and piloerection. These responses were compared during 204 trials to determine which responses occurred with and without ejaculation. Among the entire population, somatic responses were more often seen when ejaculation occurred $(71 \%$ vs. $29 \% ; p=$ $0.011)$. Specifically, piloerection ( $37 \%$ vs. $17 \% ; p=0.03)$, withdrawal response $(26 \%$ vs. $7 \% ; p=0.004)$ and extremity spasms ( $55 \%$ vs. $27 \%$; $p=0.021)$ were significantly more common with procedures resulting in ejaculation.

There were only three groups that specifically assessed the autonomic responses associated with orgasm or ejaculation with concomitant orgasm. In the two laboratory based studies $[18,21]$ of orgasm, heart rate (HR), respiratory rate $(\mathrm{RR})$ and $\mathrm{BP}$ were monitored every three minutes and at orgasm in SCIs $(N=45 \mathrm{M}, N=27 \mathrm{~F})$ and $\mathrm{AB}$ control subjects $(N=16 \mathrm{M}, \mathrm{N}=21 \mathrm{~F})$. In females, baseline and orgasm HR and BP were statistically similar between SCI and $A B$ subjects. Mean $H R$ at orgasm was 100 for $A B$ women and 96 for women with SCIs while systolic (S) BP at orgasm was $136 \mathrm{mmHg}$ for $\mathrm{AB}$ and $137 \mathrm{mmHg}$ for SCI and diastolic (D) BP was $75 \mathrm{mmHg}$ for SCI and $71 \mathrm{mmHg}$ for $\mathrm{AB}$ women. Systolic $\mathrm{BP}$ and $\mathrm{HR}$ were statistically higher in both $\mathrm{AB}$ and $\mathrm{SCI}$ women at orgasm compared to baseline; however, DBP was not. In males SBP and DBP were significantly lower at baseline in SCI subjects compared to controls; however, HR was similar between SCI and $\mathrm{AB}$ subjects. Similar to women, autonomic parameters at orgasm were similar between $\mathrm{AB}$ and SCI subjects. In males, mean HR at orgasm was 81 for SCI subjects and 90 for $\mathrm{AB}$ subjects while $\mathrm{SBP}$ was $157 \mathrm{mmHg}$ in $\mathrm{AB}$ subjects and $143 \mathrm{mmHg}$ in SCI subjects and DBP was $78 \mathrm{mmHg}$ in SCI subjects and $92 \mathrm{mmHg}$ in $\mathrm{AB}$ subjects. Of note, in a prospective laboratory-based study of a subgroup of 25 women with SCI above T6 from the larger group [18, 27], a preplanned treatment for dysreflexia was developed but not utilized as no women were clinically dysreflexic during the assessment. Similarly, of 24 men at T6 and above [21] no clinically significant dysreflexia was noted.

In two separate reports, Courtois $[12,37]$ documented a significant increase in SBP to $148-153 \mathrm{mmHg}$ at ejaculation with the use of midodrine vs. $113-118 \mathrm{mmHg}$ at baseline while DBP increased from $72-69 \mathrm{mmHg}$ at baseline to $85-91 \mathrm{mmHg}$ at ejaculation and HR decreased from 72 to $63 \mathrm{mmHg}$. These changes were not seen in tests where 
ejaculation was not achieved implying that differences in SBP were specifically related to the occurrence of ejaculation (which Courtois equated with orgasm).

Soler et al. [39] also compared the effects of ejaculation and orgasm on BP. They documented the BP changes associated with stimulation of ejaculation through the use of PVS in association with midodrine. Of 158 men with SCIs, complete files were available regarding BP in 133 individuals. Men were divided into groups as previously described. Based upon these groups, SBP was progressively greater with higher lesions. Maximum BP and HR in men with tetraplegia while on PVS with midodrine was $189 / 100 \mathrm{mmHg}$ and 54 compared to mean baseline readings of $128 / 70 \mathrm{mmHg}$ and 67 . For men with lesions at T6 and above max BP was $174 / 95 \mathrm{mmHg}$ with HR 56 compared to a baseline of $130 / 71 \mathrm{mmHg}$ and 70 . For men with lesions between T7-10 readings were $156 / 84 \mathrm{mmHg}$ and 62 vs. $126 / 71 \mathrm{mmHg}$ and 70 and for men with lesions below T10 they were $140 / 84 \mathrm{mmHg}$ and 63 vs. $128 / 72$ $\mathrm{mmHg}$ and 72 .

Other studies have described BP responses associated solely with ejaculation and not orgasm in smaller groups of subjects or without providing information about other aspects of ejaculation. In a series of 30 subjects of which 26 had injuries at T6 and above, using the vibraerect [41], highest BP at ejaculation was reported as $155 / 94 \mathrm{mmHg}$. In another study [43], 11 men of unknown injury levels were compared during PVS vs. EEJ with peak BP of 162/95 $\mathrm{mmHg}$ during PVS and $169 / 91 \mathrm{mmHg}$ during EEJ. In contrast, in a series of 13 men, the occurrence of autonomic dysreflexia (AD) during PVS performed for sperm retrieval was reported using the criteria of a $20 \mathrm{mmHg}$ increase in BP [44] and it was noted that 3 of 13 men with lesions at T6 and above had AD during PVS. Systolic and DBP was reported to be significantly higher in the subgroup of 8 men with cervical lesions at ejaculation vs. rest (190/129 vs. $83 / 55 \mathrm{mmHg} ; p<0.001$ ), but not in the 5 men with thoracic lesions. Men with complete injuries were unaware of these BP changes [45]. Moreover 5 of these subjects were noted to have bradycardia in conjunction with PVS induced ejaculation [45] whereas 7 other subjects had other arrhythmias. In a small trial [46], 6 men with SCI above T6 underwent PVS with and without the addition of prazosin to treat dysreflexia. The study reported that $1 \mathrm{mg}$ of prazosin the night before, with a repeat dose $20 \mathrm{~min}$ before stimulation, decreased the maximum increase in SBP by $40 \mathrm{mmHg}$.

Nifedipine has also been utilized to pretreat men with SCIs undergoing EEJ [47]. In a study of 10 men who had $\mathrm{AD}$ during EEJ, sublingual nifedipine reduced mean SBP from 163 to $143 \mathrm{mmHg}$ along with decreasing mean DBP from 98 to $80 \mathrm{mmHg}$.

\section{Association of orgasm and ejaculation}

With regards to the occurrence of orgasm and ejaculation, in Soler et al.'s report [11] $99 \%$ of 70 men who achieved anterograde ejaculation reported orgasm, compared to $54 \%$ of 32 men with only reflex ejaculation. Moreover, they noted that $13 \%$ of 158 men reported dry orgasm. With regards to breakdown among subgroups of orgasmic men with complete tetraplegia [4], $38 \%$ of 8 ejaculated, $28 \%$ did not ejaculate, and $25 \%$ did not know if they ejaculated. With incomplete tetraplegia, $50 \%$ of 4 subjects with orgasms reported ejaculation while the other $50 \%$ did not ejaculate. With complete paraplegia, 2 of 3 orgasmic subjects reported no ejaculation while the other did not know, and 3 orgasmic subjects with incomplete paraplegia all had concomitant ejaculation. In an online study [23] it was reported that $48 \%$ of 199 of men had achieved ejaculation post injury and $41 \%$ had orgasms. Of those men who had achieved orgasm, $89 \%$ reported ejaculations.

\section{Spasticity and ejaculation}

Four small studies [48-51] (see Supplementary Table 4) have assessed the effects of ejaculation on spasticity via PVS or electroejaculation (EEJ). Using EEJ, Halstead and Seager performed assessments of spasticity pre- and postEEJ in a total of 23 subjects including 3 females [48, 49]. These reports demonstrated the majority of subjects had over $50 \%$ relief of spasticity with an effect lasting approximately $8 \mathrm{~h}$. In another study of 9 men [50] assessing the impact of PVS on spasticity, EMG data showed a significant decrease in spasms up to three hours post PVS whereas Ashworth data showed a decrease in spasticity after ejaculation lasting an average $8 \mathrm{~h}$. Moreover, in another report of 10 men with SCIs who were monitored at baseline, 3, 5, 24 and $48 \mathrm{~h}$ after PVS [51], there was a significant decrease in spasticity as measured using the Ashworth scale both at 3 and $6 \mathrm{~h}$ post stimulation.

\section{Discussion}

This review documents the current state of our clinical knowledge regarding orgasm and ejaculation after SCI. Overall the ability to achieve orgasm is documented in about $50 \%$ of persons with SCIs with a larger percentage of women reporting the ability to achieve orgasm then men. However, overall there are limited studies available and the number of subjects in many reports is small. There is generally insufficient detail paid to whether subjects are actually sexually active when they are asked about orgasmic capabilities. A variety of questionnaires, either validated or non-validated, were used, in addition to online, phone or 
semi-structured interviews, thus reports are retrospective and subject to recall bias. There is limited data regarding specific injury characteristics and subsequently limited attempts to document the specific effects of injury patterns on sexual responses. There is a divergence in study design between various reports and there may be a bias related to desire for positive outcomes, such as in the studies [11, 25, $37,39]$ that use PVS with midodrine to facilitate the likelihood of ejaculation. Nevertheless, this review compiles the published data on orgasm and ejaculation in individuals with SCI and provides further documentation of the potential for persons with SCI to safely achieve orgasm after SCI.

Some of these data were obtained in the general SCI population via questionnaire, while other data were obtained in the laboratory. In addition to positive biases, these data may also include negative biases that need to be considered in treating persons with SCIs. Too much focus may be placed on ejaculation in men, and this may impede their ability to perceive orgasm. Persons with SCIs are on multiple medications that can negatively impact sexual function such as SSRIs, baclofen, alpha blockers and antiepileptic medications and one report [26] noted that $18 \%$ of subjects were on antidepressants. Thus, the actual capacity of persons with SCIs to achieve orgasm is probably higher. Moreover, there have been minimal attempts and clinical trials dedicated to improving orgasmic function in persons with SCI [52]. There does appear to be a subgroup of persons with SCI that are unable to achieve genitally focused orgasm, specifically, those persons with complete LMN injuries affecting their sacral segments. Unfortunately, this information is not well known by clinicians in the SCI field; and the use of the bulbocavernosus reflex and the anal wink reflexes which document the type of neuron injury affecting S3-5 are inconsistent. In order to improve or sustain the ability of persons with SCIs to achieve orgasm, it would be beneficial for clinicians to consider persons with SCIs interest in sex and consider avoiding medications with significant negative side effects on sexual function.

With regards to the subjective findings associated with orgasm, this review suggests that it takes longer for persons with SCIs to achieve orgasm, thus persons with SCI may "give up" prematurely during sex with partners or during masturbation. In one report [18], the subjective characteristics of orgasm could not be distinguished between $A B$ and SCI subjects. In another, a specific assessment of the physiologic characteristics of orgasm was addressed with a goal of developing a questionnaire to assess orgasm [12]; however, positive sensations were not elicited, the items chosen were generally of a negative nature, and the term orgasm was not used. Based upon this review, it is important to consider the potential placebo and nocebo effects communication may have on patients when discussing orgasm; moreover, this must be considered in clinical care and future studies. It is important for clinicians to educate their patients about the potential to achieve orgasm and to consider the potential bias in their own communication. Further studies of sexual function should carefully take the issue of bias into account, ensuring that attention to proper controls and optimal methodology such as double-blind, placebo-controlled treatments are utilized when possible.

Based upon the review, as demonstrated by Soler et al. [39], the terms orgasm and ejaculation cannot be equated. Thus, it is suggested that in the future both ejaculation and orgasm are considered and addressed separately in clinical care and research. A standardized method to do so is described in the International Standards for the Assessment of Autonomic Function after SCI [53, 54] and the International Spinal Cord Injury Male and Female Basic Data Sets Version 2.0 [55]. Six of the papers identified as part of this review but not included in tables [53-58] discussed formats to document sexual response. Use of the ISAFSCI $[53,54]$ for documentation of the impact of SCI on sexual response should help with identifying persons with SCIs abilities to achieve orgasm. Additionally, the International SCI Male and Female Sexual Function Data Sets [55] may be useful to monitor the effects of various treatments on orgasmic function through time.

Blood pressure increases in the SCI population with orgasm and there are further increases in BP associated with procedures such as PVS and EEJ. On the other hand, review of autonomic responses in the studies specifically assessing orgasm [18, 21, 27], revealed elevations in BP were similar between $\mathrm{AB}$ and $\mathrm{SCI}$ subjects. The studies that documented the greatest increase in BP with PVS occurred in small series $[44,45,59]$ through the use of continuous BP monitoring which may be more sensitive in detecting $\mathrm{BP}$ changes; however, the significance of a transient increase in $\mathrm{BP}$ is uncertain. The current definition of $\mathrm{AD}$ is characterized as a $20 \mathrm{~mm} \mathrm{Hg}$ increase in BP. This definition was determined clinically and by consensus [14, 53] and refinement of the definition of $\mathrm{AD}$ such as describing the length of time it needs to be present in order to classify a patient as dysreflexic seems appropriate.

With regards to potential benefits of orgasm, another important finding in this review is the reported decreased spasticity with orgasm along with the known inhibitory effect of the antispasticity medication, baclofen, on orgasm. Further studies to confirm the relationship and benefits of orgasm on spasticity and general motor function would be useful and contribute to our knowledge about the neurophysiology of orgasm and spasticity. Inclusion of females into studies of any potential benefits of orgasm on spasticity is also important. Moreover, future studies should pursue 
whether there are other benefits of regular ejaculation in areas such as increasing bladder capacity [60].

Based upon the physiologic characteristics of orgasm, it is generally associated with sympathetic activation followed by a parasympathetic response. By considering the neuroanatomy of the sympathetic chains and their connection at the ganglion impars, a neurophysiologic model of orgasm that may help explain the decrease in spasticity can be envisioned [15]. Progressively increased sympathetic stimulation results in anterograde and retrograde impulses traveling in the lumbosacral area eventually reaching a threshold where the spinal ejaculation generator responds $[61,62]$ with additional neurologic impulses resulting in ejaculation in males along with the rhythmic contractions and events associated with orgasm in both sexes. Impulses could be sent retrograde and anterograde to both the brainstem and the ganglion impars and there may be a resultant feedback loop around the genitals. In males the occurrence of ejaculation and associated cortical inhibition of the reflex would break the cycle; however, in females due to the lack of ejaculation, this loop may continue to circle in the genital area causing multiple orgasms. Based upon sympathetic neuroplasticity [63] retrograde transmission up the sympathetic chain could explain the occurrence of orgasm post SCI. This would be followed by a parasympathetic response and the resultant resolution phase. This mechanism could be similar in the $\mathrm{AB}$ population and after SCI.

To optimize the potential for maintenance of orgasm after SCI, it is important to utilize specific guidelines during patient care [64]. The clinician must determine and communicate the likely impact of the SCI on a person's responses and provide education regarding the impacts of concomitant issues such as spasticity, bladder and bowel function. Then if the individual reports sexual concerns, the clinician should consider decreasing medications with negative impacts on sexual function and consider adding other medications such as PDE5 inhibitors. Additionally, devices such as use of vibratory stimulation or the EROS [52] have recently been shown efficacious in treating neurogenic orgasmic dysfunction in women and medications such as midodrine [11] may be beneficial to improve orgasmic ability in persons with SCIs.

With regards to the issue of BP during orgasm, while there may be risks of elevated BP associated with sexual arousal to orgasm in the SCI population above T6, the majority of studies showing dangerous elevations in BP have been performed in conjunction with assisted ejaculation (PVS or EEJ) and without AB controls, thus the anxiety associated with experiencing these procedures in the presence of a clinician and the impact on BP must be considered. In contrast, in $\mathrm{AB}$ persons, orgasm induces a generalized autonomic response that includes increases in
$\mathrm{BP}, \mathrm{HR}$ and respiration and similar findings were found in SCI subjects achieving orgasm in a laboratory. Based upon these results, we believe general education for persons with injury levels at T6 about the potential for dysreflexia should be performed. Then, if complaints of dysreflexia are present the clinician should consider all potential sources and if necessary provide prophylactic medication to treat dysreflexia in association with sexual activity.

In conclusion, data show orgasm naturally occurs in approximately $50 \%$ of the SCI population and is generally safe. Benefits of orgasm such as decreased spasticity should be studied in the future. Additionally, studies must consider that both nocebo and placebo effects are possible when addressing recovery of autonomic or somatic responses after SCI and how these effects can bias results.

\section{Compliance with ethical standards}

Conflict of interest The authors declare that they have no competing interests.

\section{References}

1. Anderson KD. Targeting recovery: priorities of the spinal cordinjured population. J Neurotrauma 2004;21:1371-83. https://doi. org/10.1089/neu.2004.21.1371.

2. Siosteen A, Lundquist C, Blomstrand C, Sullivan L, Sullivan M. Sexual ability, activity, attitude and satisfaction as part of adjustment in spinal cord-injured subjects. Paraplegia 1990;28:285-95.

3. Charlifue SW, Gerhart KA, Menter RR, Whiteneck GG, Manley MS. Sexual issues of women with spinal cord injuries. Paraplegia 1992;30:192-9.

4. Alexander CJ, Sipski ML, Findley TW. Sexual activities, desire and satisfaction in males pre- and post-spinal cord injury. Arch Sex Behav. 1993;22:217-28.

5. Sipski ML, Alexander CJ. Sexual activities, response and satisfaction in women pre- and post-spinal cord injury. Arch Phys Med Rehabil. 1993;74:1025-29.

6. Harrison J, Glass CA, Owens RG, Soni BM. Factors associated with sexual functioning in women following spinal cord injury. Paraplegia 1995;33:687-92.

7. Jackson A, Wadley V. A multicenter study of women's selfreported reproductive health after spinal cord injury R. Arch Phys Med Rehabil. 1999;80:1420-8.

8. Galecki P, Depko A, Jedrzejewska S, Talarowska M. Human orgasm from the physiological perspective-part I. Pol Merkur Lekarski 2012;33:48-50.

9. Meston C, Hull E, Levin RJ, Sipski M. Disorders of orgasm in women. J Sex Med. 2004;1:66-8.

10. McMahon C, Abdo C, Incrocci L, Perelman M, Rowland D, Stuckey B, et al. Disorders of orgasm and ejaculation in men in sexual medicine: sexual dysfunctions in men and women. 2nd International Consultation of Sexual Dysfunctions 2004;411.

11. Soler JM, Previnaire JG, Plante P, Denys P, Chartier-Kastler E. Midodrine improves orgasm in spinal cord-injured men: the effects of autonomic stimulation. J Sex Med. 2008;5:2935-41.

12. Courtois F, Charvier K, Vazina JG, Journel NM, Carrier S, Jacquemin G. Assessing and conceptualizing orgasm after a spinal cord injury. BJUI 2011;108:1624-33. 
13. Krassioukov A, Elliott S, Neural control and physiology of sexual function: effect of spinal cord injury.Top Spinal Cord Inj Rehabil. 2017;23:1-10.

14. Alexander M, Courtois F. Blood pressure during sexual activity after SCI inaccurately portrayed. J Neurotrauma 2017;34:1289-90. doi:10.1090/neu.2016.4810

15. Alexander MS, Marson L. The neurologic control of arousal and orgasm with specific attention to spinal cord lesions: integrating preclinical and clinical sciences. Auton Neurosci. 2017. https:// doi.org/10.1016/j.autneu.2017.01.005

16. New PW, Currie KE. Development of a comprehensive survey of sexuality issues including a self-report version of the International Spinal Cord Injury sexual function basic data sets. Spinal Cord 2015;54:584-91.

17. Sanchez Ramos A, Vidal J, Jauregugi ML, Barrera M, Recio C, Giner $\mathrm{M}$, et al. Efficacy, safety and predictive factors of therapeutic success with sildenafil for erectile dysfunction in patients with different spinal cord injuries. Spinal Cord 2001;39:637-43.

18. Sipski ML, Alexander CJ, Rosen R. Sexual arousal and orgasm in women: effects of spinal cord injury. Ann Neurol. 2001;49:35-44.

19. Ferreiro-Velasco ME, Barca-Buyo A, de la Barrera SS. Montoto Marques, Vazquez SM, Rodriguez-Sotillo A. Sexual issues in a sample of women with spinal cord injury. Spinal Cord 2005;43:51-5.

20. Matzaroglou C, Assimakopoulos K, Panagiotopoulous E, Kasimatis G, Dimakopoulos P, Lambiris E. Sexual function in female with severe cervical spinal cord injuries; a controlled study with the Female Sexual Function Index. Int J Rehabil Res. 2005;28:375-77.

21. Sipski ML, Alexander CJ, Gomez-Marin O. Effects of level and degree of spinal cord injury on male orgasm. Spinal Cord 2006;44:798-804.

22. Anderson KD, Borisoff JF, Johnson RD, Stiens SA, Elliott SL. Spinal cord injury influences psychogenic as well as physical components of female sexual ability. Spinal Cord 2007;45:349-59.

23. Anderson KD, Borisoff JF, Johnson RD, Stiens SA, Elliott SL. Long-term effects of spinal cord injury on sexual function in men: implications for neuroplasticity. Spinal Cord 2007;45:338-48.

24. Dahlberg A, Alaranta HT, Kautianen H, Kotila M. Sexual activity and satisfaction in men with traumatic spinal cord lesion. J Rehabil Med. 2007;39:152-5.

25. Courtois F, Charvier K, Leriche A, Va JG, Ca I, Raymond D, et al. Perceived physiological and orgasmic sensations at ejaculation in spinal cord injured men. J Sex Med. 2008;3:2419-30.

26. Kreuter M, Siosteen A, Biering-Sorensen F. Sexuality and sexual life in women with spinal cord injury; a controlled study. J Rehabil Med. 2008;40:61-69.

27. Sipski ML, Alexander CJ, Rosen RC. Orgasm in women with SCIs: a laboratory-based assessment. Arch Phys Med Rehabil. 1995;76:1097-102.

28. Kreuter M, Taft C, Siosteen A, Biering-Sorensen F. Women's sexual functioning and sex life after spinal cord injury. Spinal Cord 2011;49:154-60.

29. Cardenas DD, Ditunno JF, Graziani V, McLain AB, Lammertse DP, Potter PJ, et al. Two phase 3, multicenter, randomized, placebo-controlled clinical trials of fampridine-SR for treatment of spasticity in chronic spinal cord injury. Spinal Cord 2014;52:70-76.

30. Otero-Villaverde S, Ferreiro-Velasco ME, Montoto-Marques A, Salvador de la Barrera S, Arias-Pardo AI, Rodriguez-Sotillo A. Sexual Satisfaction in women with spinal cord injuries. Spinal Cord 2015;53:557-60.

31. Sonksen J, Biering-Sorensen F, Kristensen JK, Ejaculation induced by penile vibratory stimulation in men with spinal cord injuries. The importance of the vibratory amplitude. Paraplegia. 1994;32:651-60.

32. Ohl DA, Menge AD, Sonksen J. Penile vibratory stimulation in spinal cord injured men: optimized vibration parameters and prognostic factors. Arch Phys Med Rehabil. 1996;77:903-05.

33. Denys P, Mane M, Azouvi P, Chartier-Kastler E, Thiebaut J, Bussel B. Side effects of chronic intrathecal baclofen on erection and ejaculation in patients with spinal cord lesions. Arch Phys Med Rehabil. 1998;79:494-96.

34. Wieder JA, Brackett NL, Lynne CM, Green JT, Aballa TC. Anesthetic block of the dorsal penile nerve inhibits vibratoryinduced ejaculation in men with spinal cord injuries. Urology 2000;55:915-17.

35. Bird VG, Brackett NL, Lynne CM, Aballa TC, Ferrell SM. Reflexes and somatic responses as predictors of ejaculation by penile vibratory stimulation in men with spinal cord injury. Spinal Cord 2001;39:514-19.

36. Brackett JL, Kafetsoulis A, Ibrahim E, Aballa TC, Lynne CM. Application of 2 vibrators salvages ejaculatory failures to 1 vibrator during penile vibratory stimulation in men with spinal cord injuries. J Urol. 2007;177:660-63.

37. Courtois FJ, Charvier KF, Leriche A, Vezina JG, Cote M, Belanger M. Blood pressure changes during sexual stimulation, ejaculation and midodrine treatment in men with spinal cord injury. BJUI 2007;101:331-37.

38. Giuliano F, Rubio-Aurioles E, Kennelly M, Montorsi F, Kim ED, Finbeiner AD, et al. Vardenafil improves ejaculation success rates and self-confidence in men with erectile dysfunction due to spinal cord injury. Spine 2008;3:709-15.

39. Soler JM, Previnaire JG, Plante P, Denys P, Chartier-Kastler E. Midodrine improves ejaculation in spinal cord injured men. J Urol. 2007;178:2082-86.

40. Biering-Sorensen I, Hansen RB, Biering-Sorensen F. Sexual function in a traumatic spinal cord injuries population 10-45 years after injury. J Rehabil Med. 2012;44:926-31.

41. Castle SM, Jenkins LC, Ibrahim E, Aballa TC, Lynne CM, Brackett NL. Safety and efficacy of a new device for inducting ejaculation in men with spinal cord injuries. Spinal Cord 2014;52: S27-S29.

42. Leduc BE, Fournier C, Jacquemin G, Lepage Y, Vinet B, Hetu P, et al. Midodrine in patients with spinal cord injury and anejaculation; a double-blind randomized placebo-controlled pilot study. J Spinal Cord Med. 2015;38:57-62.

43. Ohl DA, Sonksen J, Menge AC, McCabe M, Keller LM. Electroejaculation versus vibratory stimulation in spinal cord injured men: sperm quality and patient preference. $J$ Urol. 1997; 157:2147-49.

44. Sheel AW, Krassioukov AV, Inglis JT, Elliot SL. Autonomic dysreflexia during sperm retrieval in spinal cord injury: influence of lesion level and sidenafil citrate. J Appl Physiol. 2005;99:53-8.

45. Claydon V, Elliott S, Sheel A, Krassioukov A. Cardiovascular responses to vibrostimulation for sperm retrieval in men with spinal cord injury. J Spinal Cord Med. 2006;29:207-16.

46. Phillips AA, Elliott SL, Zheng MM, Krassioukov AV. Selective alpha adrenergic antagonist reduces severity of transient hypertension during sexual stimulation after spinal cord injury. J Neurotrauma 2015;32:293-304.

47. Steinberger R, McCabe M, Ohl DA, Wang SC, Bennett CJ. Nifedipine pretreatment for autonomic dysreflexia during electroejaculation. Urology 1990;36:228-31.

48. Halstead LS, Seager SWJ. The effects of rectal probe electrostimulation on spinal cord injury spasticity. Paraplegia 1991;29:43-7.

49. Halstead LS, Seager SW, Houston JM, Whitesell K, Dennis M, Nance PW. Relief of spasticity in SCI men and women using rectal problem electrostimulation. Paraplegia 1993;31:715-21. 
50. Laessoe L, Nielsen JB, Biering-Sorensen F, Sonkson J. Antispastic effect of penile vibration in men with spinal cord lesion. Arch Phys Med Rehabil. 2004;85:919-24.

51. Alace R, Goktepe AS, Yildiz N, Yilmaz B, Gunduz S. Effect of penile vibratory stimulation on spasticity in men with spinal cord injury. Am J Phys Med Rehabil. 2005;84:875-79.

52. Alexander MS, Bashir K, Marson L, Alexander C, Rosen R. Efficacy of clitoral vacuum suction and vibratory stimulation in neurogenic female orgasmic dysfunction. Arch Phys Med Rehabil. 2017. https://doi.org/10.1016/j.apmr.2017.09.001

53. Alexander MS, Biering-Sorensen F, Bodner D, Brackett NL, Cardenas D, Charlifue $\mathrm{S}$, et al. International standards to document remaining autonomic function after spinal cord injury. Spinal Cord 2009;47:36-43.

54. Krassioukov A, Biering-Sorensen F, Donovan W, Kennelly M, Kirshblum S, Krogh K, et al. International standards to document remaining autonomic function after spinal cord injury. J Spinal Cord Med. 2012;35:201-10.

55. Alexander M, New P, Biering-Sorensen F, Courtois F, Del Popolo $\mathrm{G}$, Elliott $\mathrm{S}$, et al. International spinal cord injury male sexual function and female sexual and reproductive function basic data sets - version 2.0. Spinal Cord Ser Cases 2017;3:17050 https://doi. org/10.1038/scsandc.2017.50.

56. Alexander MS, Biering-Sorensen F, Elliott S, Kreuter M, Sonksen J, International spinal cord injury female sexual function basic data set.Spinal Cord 2011;49:787-90.

57. Alexander MS, Biering-Sorensen F, Elliott S, Kreuter M, Sonksen J, International spinal cord injury male sexual function basic data set. Spinal Cord 2011;49:795-98.
58. Sipski ML. Documentation of the impact of spinal cord injury on sexual function: the female spinal sexual function classification. Topic SCI Rehabil. 2002;8:63-73.

59. Ekland M, Krassioukov A, McBride K, Elliott S. Incidence of autonomic dysreflexia and silent autonomic dysreflexia in men with spinal cord injury undergoing sperm retrieval: Implications for clinical practice. J Spinal Cord Med. 2008;31:33-39.

60. Laessoe L, Sonksen J, Bagi P, Biering-Sorensen F, Ohl D, McGuire E, et al. Effects of ejaculation by penile vibratory stimulation on bladder capacity in men with spinal cord lesions. J Urol. 2003;169:2216-19.

61. Kozyrev N, Figley C, Alexander M, Richards J, Bosma R, Stroman P. Neural correlates of sexual arousal in the spinal cords of able-bodied men: a spinal fMRI investigation. J Sex Marital Ther. 2012;38:418-35.

62. Alexander M, Kozyrev N, Figley CR, Richards S. Altered spinal cord activity during sexual stimulation in women with SCI: a pilot fMRI study. Spinal Cord Ser Cases 2017;3:16041 https://doi.org/ 10.1038/scsandc. 2016.41

63. Mclachlan E. Diversity of sympathetic vasoconstrictor pathways and their plasticity after spinal cord injury. Clin Auton Res. 2007; 17:6-12.

64. Alexander MS, Courtois F, Elliott S, Tepper M, Improving the ability of persons with spinal cord injury to achieve orgasm: collective wisdom. Topic SCI Rehabil. 2017;23: $57-70$.

65. Sønksen J, Ohl DA, Wedemeyer G. Sphincteric events during penile vibratory ejaculation and electroejaculation in men with spinal cord injuries. J Urol. 2001;165:426-429. 